\title{
A Biblioteca de Babel e o Outro: Borges e Lacan
}

\section{The Library of Babel and the Other: \\ Borges and Lacan}

\author{
Vitor Hugo Couto Triska*1 \\ Marta Regina de Leão D’Agord*2
}

\begin{abstract}
No conto "A Biblioteca de Babel", Borges ensaiou aproximações com a matemática, a lógica, a filosofia e a psicopatologia. Este artigo promove um encontro metodológico de Borges com Lacan, afirmando a potência da articulação entre ficção literária e pensamento formal. Através da topologia do toro, propõe-se uma homologia estrutural entre a Biblioteca e o Outro, permitindo uma comparação das diferentes posições das personagens do conto com as do sujeito na linguagem.
\end{abstract}

Palavras-chave: Psicanálise, psicopatologia, literatura, topologia

*1 Psicanalista, atende em consultório particular (Porto Alegre, RS, Br).

*2 Universidade Federal do Rio Grande do Sul - UFRGS (Porto Alegre, RS, $\mathrm{Br})$. 
Interessadas nas experiências humanas que fogem ao comum, Literatura e Psicopatologia caminham em paralelo, mas não raro encontram pontos de encontro. Assim como frequentemente encontramos o ficcionista usando o conteúdo e a linguagem da psicopatologia, personagens e autores tornam-se modelos, nomes ou testemunhos do psicopatológico. Seguindo por um caminho mais lateral, o conto "A Biblioteca de Babel”, de Jorge Luis Borges, não se deixa apreender em uma classificação, pois diz de uma experiência limite universal, a finitude. Se tomarmos, porém, a Biblioteca como alteridade constituinte diante da qual há diferentes modos de situar-se, além de uma comparação com o conceito de Outro em Lacan, cria-se a possibilidade de uma investigação psicopatológica das posições do sujeito na linguagem.

\section{A linguagem criadora}

Como outros pensadores que concebem a linguagem como potência criadora de realidades, para Lacan (1953-1954/1986) “os conceitos têm sua ordem de realidade original" (p. 10), de forma que as primeiras denominações surgem das próprias palavras. Primeiramente, destaca-se uma dimensão epistemológica - a realidade original vem dos conceitos, dá-se no sentido do método ao objeto e não o contrário. Lacan adota a concepção de ciência de Koyré (1973/2011), o que implica um rebaixamento do empírico diante das descobertas realizadas matematicamente e a priori. De acordo com essa perspectiva, o real não é dado a conhecer empírica e independentemente dos conceitos; muito pelo contrário, são estes que, elaborados racionalmente, ordenam e criam fenômenos 
circunscritos. Dada a influência de Koyré, compreende-se a razão pela qual Lacan nega a existência de qualquer realidade pré-discursiva, pois a linguagem seria logicamente anterior a qualquer realidade. A noção de estrutura em Lacan, portanto, não é a descrição de um sistema natural e aparente, tampouco um modelo teórico abstrato e distante da experiência. Trata-se de uma terceira via que considera "os efeitos que a combinatória pura e simples do significante" na produção da realidade, de modo que a estrutura seria uma "máquina original" (Lacan, 1960/1998b, p. 655).

A epígrafe do conto de Borges (1944/2015, p. 69) toma a literatura como uma arte baseada na combinação de letras: "Por esta arte você pode contemplar a variação das 23 letras". ${ }^{1}$ Borges reconhece a potência dessa ideia e a utiliza para conceber uma Biblioteca "total" onde estão "todas as possíveis combinações dos vinte e tantos símbolos ortográficos (número, ainda que vastíssimo, não infinito), ou seja, tudo o que é dado expressar: em todos os idiomas" (p. 73). Além de todas as histórias, conhecimentos e ficções, e mais do que as realidades passadas, presentes e futuras, seus livros contêm todas as realidades possiveis. Como em Lacan, no conto de Borges qualquer realidade está atrelada à linguagem e aquela é uma realização desta, de forma que impossivel seria o que não pode ser exprimido por uma das combinações dos símbolos. Ora, pode existir algo que não seja exprimível? O que pode não estar na Biblioteca?

\section{A topologia da Biblioteca}

O narrador do conto afirma que a hipótese mais aceita entre os habitantes da Biblioteca é a de que a combinação dos símbolos não se dá nela de forma livre, mas em livros de características invariáveis, em galerias cujas formas hexagonais e número de prateleiras também são invariáveis. Uma vez que nenhum homem pôde percorrer totalmente a imensa Biblioteca para averiguar se o padrão é observável em toda sua extensão, ${ }^{2}$ a uniformidade de sua estrutura só pode ser considerada uma hipótese. Entre as várias regularidades

${ }^{1}$ Tradução livre de By this art you may contemplate the variation of the 23 letters..., trecho de Anatomy of Melancholy, de Robert Burton.

${ }^{2}$ Um cálculo aproximado demonstra que a Biblioteca é maior que nosso universo observável. 


\section{LITERATURA, ARTE, PSICOPATOLOGIA}

descritas pelo narrador, algumas serão importantes por serem regularidades quaisquer, pois sustentam a ideia de que há uma lei fundamental que padroniza a Biblioteca: cada parede de cada hexágono possui cinco prateleiras com 32 livros de formato uniforme (número de páginas, linhas etc.) (Borges, 1944/2015, p. 70). Outras regularidades são decisivas por atestarem a finitude da Biblioteca, como a constatação de que todos os livros possuem os mesmos símbolos (22 letras, espaço, ponto e vírgula) e que não há dois livros iguais (p. 73). Como no xadrez, em que há regras, número definido de peças e, logo, as possibilidades de jogos possíveis são contáveis, a Biblioteca, se houver ordem e um número dado de elementos combinados, deve ser finita.

Embora a sua estrutura e organização sejam notáveis, não se sabe se ela mantém essa estrutura em todas as partes. Se assumimos que as partes ainda não percorridas estão estruturadas da mesma maneira que as demais, a Biblioteca deve ser considerada homogênea e finita, afinal, há um número finito de livros. Segundo o narrador, "a biblioteca é uma esfera cujo verdadeiro centro é qualquer hexágono" (Borges, 1944/2015, p. 70), ou seja, nenhum hexágono ou livro seria especial. Como um conjunto de significantes, cada um é tão somente um elemento de um sistema não hierárquico de oposições. Ao conceber a Biblioteca como esférica, o narrador parece aceitar a necessidade lógica de que ela seja finita, mas ainda assim a considera "interminável" (p. 70), pois "periódica" (p. 78). Segunda essa ideia, a Biblioteca seria finita, contável, mas circular, sem fim nem começo.

Eidelsztein (2008) contribui para essa discussão ao valorizar a distinção entre bateria e tesouro do significante. O primeiro caso diz respeito à perspectiva de que "toda língua é completa para significar tudo o que um falante dela necessite ou queira comunicar" (p. 50); tudo que é exprimível o será através da bateria dos significantes. No segundo caso, o do tesouro, considera-se o conjunto como incompleto, faltante. O Outro lacaniano requereria a coexistência das dimensões da bateria e do tesouro, pois enquanto conjunto de significantes, ele é não só o lugar onde estes adquirem todo significado possível, mas também de uma falta que permite a covariação dos significantes e a produção de novos sentidos. A noção de covariação "designa o fato de que cada um dos elementos é, não o que ele aparenta ser, mas um lugar vazio no sistema de relações que mantém com todos os outros" (Eidelsztein, 2008, p. 51). Se não houvesse uma falta no Outro, se este fosse apenas um código, não existiria a covariação dos significantes, pois estariam fixados aos significados. O efeito poético e o mal-entendido, portanto, só são possíveis pela dimensão de tesouro (faltante) do Outro. 
Como o Outro, a Biblioteca pode ser apreendida como uma totalidade que porta uma falta. Lembrando que a própria palavra "biblioteca" pode significar "pão" ou "pirâmide" em outra língua, Borges bem expressa a insuficiência da Biblioteca em garantir significados: "Tu, que me lês, estás seguro de entender minha linguagem?" (1944/2015, p. 78). Segundo Lacan (1968-1969/2008), “a linguagem em sua essência não significa nada” (p. 87) É, paradoxalmente, por não significar necessariamente nada que a Biblioteca é total e contém tudo que é exprimível.

Quando morto, o narrador deseja que seu corpo seja atirado em um dos poços da Biblioteca: "minha sepultura será o ar insondável; meu corpo afundará longamente e se corromperá e dissolverá no vento gerado pela queda" (Borges, 1944/2015, p. 70). O vazio dos poços contrasta com as numerosas prateleiras de livros que os cercam e dão a própria imagem da ostensiva totalidade da Biblioteca que, paradoxalmente, abriga enigmas e hiâncias. O vazio, porém, não é necessariamente um lugar físico na Biblioteca, mas insuficiência em sua estrutura. A estrutura do Outro apresentada por Lacan a partir da topologia do toro (1961-1962/2003a, 1968-1969/2008) permite conceber a Biblioteca como topologicamente estruturada.

Muito embora sirva como uma imagem intuitiva possível do que poderia ser o centro da Biblioteca ao mesmo tempo finita (pois embora numerosos, seus livros são contáveis) e interminável (pois periódica e circular), será a estrutura bidimensional do toro que servirá para sua consideração topológica. Lacan (1961-1962/2003a) encontra a função da demanda (D) nos círculos plenos do toro, ao passo que o objeto $a$, causa de desejo, será localizado no círculo vazio - a volta que resta não contada nas repetições da demanda. Destaca-se assim o objeto $a$ como nome da falta no Outro.
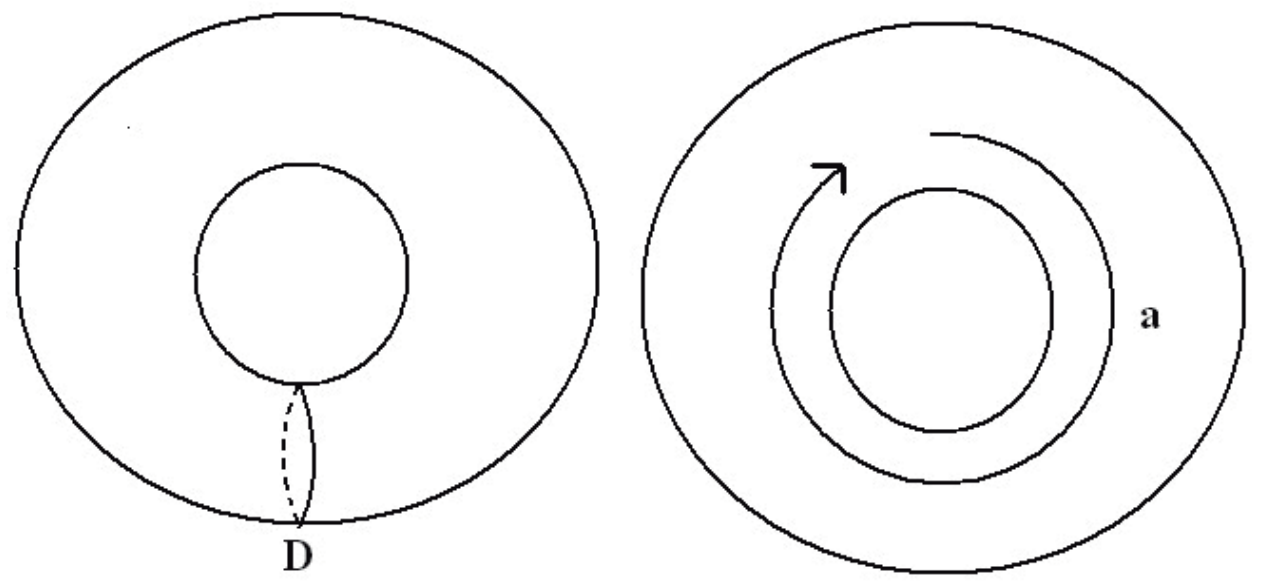

Figura1 


\section{LITERATURA, ARTE, PSICOPATOLOGIA}

Posteriormente, Lacan (1968-1969/2008) desenvolve a topológica do Outro tórico pela teoria dos conjuntos e do Paradoxo de Russell. Para tanto, considera que cada elemento do conjunto A (Outro) é também um subconjunto capaz de conter outros elementos-conjuntos. Nessa esquematização, $\mathrm{S} 2$, contido em A, é o conjunto que contém todos os conjuntos que não contêm a si mesmos e estão incluídos em A. Chamemos de Sx, Sy e Sz os elementos que satisfazem essas duas condições. Surgem duas opções: (a) se S2 não está incluído nele mesmo, ele necessariamente deve conter-se, mas (b) se ele contém a si mesmo, isso não está de acordo com a função de que contenha apenas elementos que não contém a si mesmos e, logo, ele deverá estar fora - eis o paradoxo. Ora, se para estar contido em S2 um elemento deve também estar incluído em A, a conclusão à qual chega Lacan (1968-1969/2008, p. 74) é que S2 não está contido em A, muito embora seus elementos estejam. É o que ilustra com a figura seguinte:

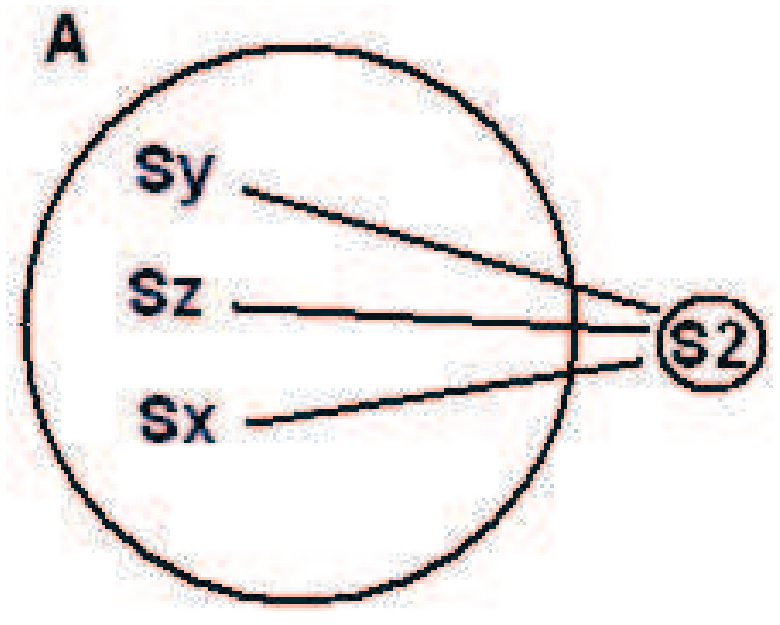

Figura 2

O que se articula como significante deve deixar um elemento obrigatoriamente fora de A (Lacan, 1968-1969/2008, p. 74), o que faz do Outro um conjunto incompleto. Por sua homologia estrutural, isto é, conjunto de saberes ao mesmo tempo total e incompleto, mas também por sua função de alteridade radical de linguagem, consideraremos a Biblioteca como o Outro lacaniano.

A perguntas dos habitantes da Biblioteca são análogas às nossas questões e tentativas de explicações (científicas, religiosas etc.) sobre as origens e leis do Universo: "Também se esperou então o esclarecimento dos mistérios básicos da humanidade: a origem da Biblioteca e do tempo". 
(Borges, 1944/2015, p. 74). Devido à sua ordenação, há os que concluem que ela "somente pode ser obra de um deus" (p. 71). Supersticiosos antigos criam em um livro que fosse "a chave e compêndio perfeito de todos os demais", cultuando o bibliotecário que o teria lido como um deus (p. 76). Outros buscavam um hexágono cheio de livros "onipotentes, ilustrados e mágicos" (p. 76). O narrador cita peregrinações por um "catálogo dos catálogos" (p. 70) e roga aos deuses que ao menos um homem tenha encontrado o "livro total", lembrando que, se da Biblioteca só fica excluído o impossível, tal livro deve existir (p. 76). Essas hipóteses são diferentes formas da busca por algo que justifique e explique a Biblioteca e, enfim, a existência de seus habitantes. Mas a Biblioteca parece não poder explicar a si própria. A falta de um elemento diferenciado, como um referente que garanta estabilidade aos significados das palavras, faz dela um Outro total e enigmático.

\section{A psicopatologia na Biblioteca}

Por corresponderem a relações entre o Outro e o sujeito, podemos comparar situações de homens diante da Biblioteca com as três principais estruturas clínicas: neurose, psicose e perversão. A busca por um elemento diferente, responsável pela ordenação da Biblioteca como se fosse uma exigência lógica (há de haver ao menos $U m$ ), remete à pergunta do neurótico sobre sua origem e à fantasia de que há Pai. A suposição de um "Pai ideal", castrador e não castrado, é chamada por Lacan de "fantasia de neuróticos". A verdadeira função do Pai, porém, seria "unir (e não opor) um desejo à Lei" (Lacan, 1960/1998c, p. 839). Quando essa Lei não opera, isto é, a foraclusão do Nome-do-Pai determina uma estrutura psicótica, Lacan considera que há um buraco aberto no campo significado. Seu preenchimento se daria através de uma "cascata de remanejamentos do significante" que, por um "desastre crescente do imaginário" (1957-1958/1998a, p. 584), chegariam ao estabelecimento de uma metáfora delirante onde significante e significado se estabilizam (p. 584). Como no caso Schreber, é a construção de uma totalidade delirante que regula a relação do psicótico com o Outro. Diante da impossibilidade de simbolizar a falta do Outro que produz a dimensão equívoca da linguagem, busca-se uma estabilização delirante entre significantes e significados. Finalmente, consideremos a descrição lacaniana do perverso como "defensor da fé" (1968-1969/2008, p. 245), aquele que se dedica a tapar a 


\section{LITERATURA, ARTE, PSICOPATOLOGIA}

falta no Outro, mantendo-o completo, não castrado. Ainda que reconhecendo a falta irredutível, trata-se de desmenti-la.

São três diferentes formas de operar com a falta na Outro. O neurótico, para quem a Biblioteca é ao mesmo tempo ordenada e enigmática, monta a fantasia de que há um Pai responsável por essa ordenação para responder à pergunta por sua origem. No conto, servem de exemplo as formas de procura pelo Livro dos livros ou Catálogo dos catálogos, algo que responda às perguntas neuróticas. Para o psicótico a desordem da Biblioteca busca ser sanada com uma ordenação delirante que funcione como suplência da não inscrição da Lei no Outro. Como exemplo dessa posição, temos os místicos que "pretendem que o êxtase lhes revele uma câmara circular com um grande livro circular de lombada contínua, que dá toda a volta nas paredes" (Borges, 1944/2015, p. 70), isto é, um elemento ao mesmo tempo divino e material, equivalente a Deus, que ordene a realidade. Na neurose essa realidade já está ordenada, de forma que as buscas por um elemento especial têm a forma de hipóteses e perguntas. $\mathrm{Na}$ psicose, por sua vez, visto que ocorreu a foraclusão de um elemento que retornará no Real, é no próprio estado de êxtase ou delirante que esse elemento será encontrado. No caso do perverso, por fim, a Biblioteca está colocada em sua dimensão de totalidade faltante da mesma maneira que na neurose. Uma desmentida da falta, porém, acontecerá por uma père-version - uma versão da Lei paterna onde a falta pode ser imaginariamente preenchida. Como exemplo, os homens da seita blasfemam que sugere cessar a busca por livros especiais, propondo que se baralhe letras e símbolos até construir "livros canônicos" (p. 75), ou seja, produzir aquilo que falta ao Outro, completando-o.

Há também uma dimensão psicopatológica nos dois polos descritos por Borges (1944/2015) como "desmedida esperança" e "depressão excessiva" (p. 75). A primeira diz respeito à "certeza de que alguma prateleira em algum hexágono encerrava livros preciosos", enquanto a segunda à constatação de que esses livros são "inacessíveis", o que seria "quase intolerável" (p. 75). A esperança teria gerado a busca pelas indicações: "livros de apologia e profecia, que justificavam para sempre os atos de cada homem do universo" (p. 74). A procura por esses livros, porém, teria levado os homens à loucura e a brigas mortais (p. 74), como se a desmedida esperança fosse tão mortal quanto seu polo oposto, a saber, a depressão excessiva - causa dos numerosos suicídios que contribuem para diminuição do número de habitantes (p. 72).

"A certeza de que tudo está escrito nos anula ou faz de nós fantasmas", afirma Borges (1944/2015, p. 78) através do narrador. Tão ou mais importante do que os diferentes posicionamentos diante da Biblioteca que comparamos 
com estruturas clínicas, destaca-se a dificuldade de suportar qualquer posição. A Biblioteca não esclarece seus próprios enigmas, não dá garantias que sustentem alguma posição. Depois do desaparecimento de todos os homens, afirma o narrador, ela permanecerá "iluminada, solitária, infinita, perfeitamente imóvel, armada de volumes preciosos, inútil, incorruptível, secreta" (p. 78) e, acrescentaríamos, indiferente. O contraste entre sua totalidade e sua falta de sentido é constante. Entre a esperança e a depressão descritas por Borges, destacaríamos esta última. Não tomaremos o termo depressão de acordo com as classificações do psicopatológico, mas como uma dimensão da melancolia. A totalidade da Biblioteca, o fato de ela conter todas as versões possíveis da vida de um homem, anula-o. Se tudo já está escrito, é impossível realizar qualquer possibilidade que já não esteja prevista. Faça o que fizer, ele tão somente confirmará algo que um livro qualquer, uma combinação despropositada de letras, prevê.

Em Freud (1917[1915]/2010), a melancolia se caracteriza pela perda de um objeto com o qual se mantém uma identificação narcísica, de modo que a relação ambivalente com esse objeto (amor e ódio) explicaria a relação de desprezo do melancólico com seu Eu, como um sadismo voltado para si mesmo que surge em substituição à impossibilidade de integrar à consciência a hostilidade ao objeto. Freud aponta a tendência ao suicídio na melancolia como forma substitutiva do ódio que é originalmente direcionado para o objeto. A mania seria uma espécie de torsão da melancolia, o estado em que o Eu supera a perda do objeto e em que toda a libido até então investida de maneira hostil no Eu é redirecionada intensamente.

Seria um estado melancólico o daqueles homens que, pela depressão excessiva, suicidam-se na Biblioteca? Se considerarmos que o melancólico manifesta sua ambivalência à Biblioteca pela hostilização do próprio $\mathrm{Eu}$, então a resposta é afirmativa. Seria o caso dos homens que, diante da totalidade do Outro e da perda de sentido resultante da constatação de que os livros de conteúdo crucial são tão numerosos quanto inacessíveis, direcionam o ódio da Biblioteca para o Eu. O suicídio, portanto, surge como consequência da depressão excessiva, comparável à melancolia, como alternativa de fuga da apreensão totalizante da Biblioteca e também da insignificância da vida de um homem diante dela. A continuidade desse estado com a desmedida esperança se dá por meio de uma torsão equivalente ao que acontece na articulação entre melancolia e mania. No momento em que a libido investida no Eu é redirecionada à Biblioteca, a sua dimensão de totalidade valiosa é readquirida. Encontramos, mais uma vez, a desmedida esperança, também de a "extravagante felicidade" dos homens quando "se sentiram senhores de um tesouro 


\section{LITERATURA, ARTE, PSICOPATOLOGIA}

intacto e secreto", afinal, "não havia problema pessoal ou mundial cuja eloquente solução não existisse: em algum hexágono" (Borges, 1944/2015, p. 74). Esse trecho, que exalta a felicidade dos homens diante da descoberta de um tesouro, ao terminar com "em algum hexágono", demonstra o contraste entre a riqueza do universo de livros que cerca os homens e a sua inacessibilidade. A proximidade lógica entre melancolia e a mania encontra em Borges uma demonstração literária.

\section{O filósofo, o sofista e o lacaniano na Biblioteca}

O narrador debate com "ímpios" que dizem que a Biblioteca é quase toda disparate e que exceções razoáveis são "uma milagrosa exceção" (Borges, 1944/2015, p. 77). Lembrando que ela inclui todas as combinações possíveis dos símbolos, defende que não há disparate, pois não haveria nenhuma combinação que "em alguma de suas línguas secretas não encerrem um sentido terrível" (p. 77). Se cada palavra significa algo, isto não quer dizer que todas combinações tenham um significado fixo, mas, pelo contrário, que todas elas podem significar qualquer coisa. O que falta é uma garantia.

Segundo Badiou (2003, p. 15), o filósofo e o sofista fazem uso da mesma retórica e das mesmas referências, divergindo apenas no que diz respeito à consideração da existência de uma verdade. O sofista recusa a existência desta; tudo é redutível a jogos de linguagem vazios e não há verdade que imponha obstáculos a eles, tomando a língua como uma "superfície lúdica" (p. 22). A filosofia, por sua vez, seria o modo de pensamento que reconhece no acontecimento um obstáculo irredutível às regras da língua, como uma verdade que nos coloca em suspenso (p. 15). Embora considere Lacan um antifilósofo, Badiou (p. 16) não identifica o psicanalista aos sofistas, pois ele reconheceria uma verdade para além dos enunciados, algo que escapa ao saber e articula o sujeito do inconsciente. Para o sofista a Biblioteca seria tão somente um embaralhado de letras em que qualquer coisa pode ser dita e qualquer palavra vale por outra; para o filósofo a Biblioteca teria um referente e por isso ela não pode ser tomada como um conjunto de enunciados equivalentes, pois pelo menos um se apoia sobre uma verdade; para Lacan, finalmente, há também uma verdade, mas mais além dos enunciados, em um ponto de falha de saber.

Apoiado em Gödel, Lacan (1962-1963/2003a) afirma que há um "resíduo obrigatoriamente indemonstrável" no "campo da criação matemática" 
(p. 165), ao que apenas a exploração logicizante pode nos conduzir. A referência lacaniana a Gödel diz respeito à prova de que, em um sistema aritmético, há proposições verdadeiras que não podem ser dedutíveis dentro do próprio sistema (Goldstein, 2008, p. 131). O matemático demonstra ser impossível provar a consistência de um sistema aritmético a partir dele mesmo (p. 137). Lacan inspira-se na prova de Gödel para sustentar a estrutura do sujeito na própria hiância revelada pelo impasse lógico-matemático: "Da tenuidade de sua cicatriz, ou, melhor ainda, de sua hiância, as aporias da lógica matemática dão testemunho (teorema de Godel), sempre para escândalo da consciência (1966/2003b, p. 207). Badiou (2003) propõe que é a referência a Gödel que permite a Lacan uma "ultrapassagem" sobre a filosofia de Platão, uma vez que, se há verdades que não podem ser dedutíveis pelo cálculo dentro de um sistema aritmético, "a impossibilidade estrutural de decisão vai contra o que Platão supõe no Menon, a saber, que as ideias matemáticas são inatas" (p. 35). Assim, Gödel impediria de sustentar a concepção platônica de que a matemática encontra seu suporte "na forma de Ideia eterna inscrita enquanto tal na parte dianoica da nossa alma" (p. 35).

Esta discussão nos serve para interrogar a Biblioteca enquanto Outro 176 de uma nova maneira. O Outro é a bateria dos significantes, isto é, tem sua dimensão de totalidade onde tem lugar tudo que é exprimível, mas também abriga uma falta, ou seja, é um tesouro incompleto. Como a Biblioteca, o Outro não explica ou significa a si mesmo. Eis o sentido das afirmações lacanianas acerca da inexistência da verdade da verdade, da linguagem sobre a linguagem (metalinguagem) e, finalmente, do Outro do Outro.

\section{Considerações finais: a escrita e a intuição}

Borges dirigiu e prologou uma coleção de livros selecionados chamada Biblioteca Pessoal, onde consta Mathematics and the imagination, de Kasner e Newman (1940/2001). No prólogo deste, o escritor argentino afirma que "a imaginação e as matemáticas não se contrapõem; complementam-se como a fechadura e a chave" (1987, p. 11). Como exemplo dessa ideia, Borges cita a geometria tetradimensional e o estudo dos hipervolumes - como a hiperesfera e o hipercubo - , objetos que "não sabemos se existem, mas conhecemos suas leis" (p. 11). Essa dimensão pura da matemática, que não trata de objetos empíricos e dados, mas daqueles existentes somente em uma realidade matemática, é enfatizada por Kasner e Newman — há uma realidade 


\section{LITERATURA, ARTE, PSICOPATOLOGIA}

abordável apenas pela matemática. Encontramos uma influência desse raciocínio em Lacan (1971/2009, p. 94) quando, por exemplo, pede aos ouvintes de seu seminário que, a dois pontos dados, acrescente-se um terceiro, equidistante aos demais, obtendo um triângulo, bidimensional. Ao acrescentar um novo ponto equidistante aos três já colocados obtém-se um tetraedro de quatro vértices, tridimensional. Até aqui esse exercício não coloca problemas à nossa intuição, pois é possível conceber e visualizar mentalmente o triângulo e o tetraedro. Se mais um ponto equidistante aos quatro já colocados for adicionado ao esquema, porém, será preciso uma quarta dimensão, pois apenas em um espaço de quatro dimensões se pode colocar cinco pontos equidistantes. Neste ponto a intuição encontra um limite que só pode ser transposto com o suporte da escrita: "para além do tetraedro, a intuição já tem que se apoiar na letra" (p. 95). Esse exercício revela uma orientação epistemológica, pois ao considerar a lógica como ciência do Real, justamente no seminário em que investiga, entre outros matemas, as fórmulas da sexuação, Lacan (1971/2009) demonstra que, como acontece na matemática pura, o raciocínio sustentado pela escrita lógico-matemática permite abordar um mais além da realidade o Real.

Quando cotejadas, matemática e imaginação, ou escrita e intuição, revelam antes uma aproximação do que uma oposição, como Borges percebe e demonstra. A investigação do psicopatológico, portanto, já bastante consagrada pela literatura, a partir da aproximação desta com a escrita lógico-matemática, encontra uma via produtiva a ser explorada. O uso lacaniano de ferramentas formais de forma alguma trata de formalizar uma teoria já dada, pois assim seria tão somente uma outra forma de representar conceitos existentes. Topologia e lógica - tanto quanto a literatura que a elas pode se articular - servem a Lacan como uma escrita que permite investigar e criar um espaço que, por outras vias, não poderia sê-lo.

\section{Referências}

Badiou, A. (2003). Lacan e Platão: o matema é uma ideia? In W. Safatle (Org.), Um limite tenso: Lacan entre a filosofia e a psicanálise (pp. 13-41) São Paulo, SP: Editora UNESP.

Borges, J. L. (2015). A Biblioteca de Babel. In Ficções (pp. 69-79). São Paulo, SP: Companhia das Letras. (Trabalho originalmente publicado em 1944). 
Borges, J. L. (1987). Prólogo. In E. Kasner, \& J. Newman, Matemáticas e imaginácion (p. 11). Barcelona: Ediciones Orbis.

Eidelsztein, A. (2008). Las estructuras clínicas a partir de Lacan (vol. I, 2 ${ }^{\mathrm{a}}$ ed.). Buenos Aires: Letra Viva.

Freud, S. (2010). Luto e melancolia. In Obras completas (vol. 12, pp. 127-144). São Paulo, SP: Companhia das Letras. (Trabalho original publicado em 1917[1915]).

Goldstein, R. (2008). Incompletude: a prova e o paradoxo de Kurt Gödel. São Paulo, SP: Companhia das Letras.

Kasner, E., \& Newman, J. (2001). Mathematics and the imagination. New York: Dover Publications, Inc. (Trabalho original publicado em 1940).

Koyré, A. (2011). Estudos de História do Pensamento Científico ( $3^{\mathrm{a}}$ ed.). Rio de Janeiro, RJ: Forense. (Trabalho original publicado em 1973).

Lacan, J. (1986). O seminário. Livro 1. Os escritos técnicos de Freud. Rio de Janeiro, RJ: Jorge Zahar. (Trabalho original publicado em 1953-1954).

Lacan, J. (1998a). De uma questão preliminar a todo tratamento possível da psicose. In Escritos (pp. 537-590). Rio de Janeiro, RJ: Jorge Zahar. (Trabalho original publicado em 1957-1958).

Lacan, J. (1998b). Observação sobre o relatório de Daniel Lagache. In Escritos (pp. 653-691). Rio de Janeiro, RJ: Jorge Zahar. (Trabalho original publicado em 1960).

Lacan, J. (1998c). Subversão do sujeito e dialética do desejo no inconsciente freudiano. In Escritos (pp. 807-842). Rio de Janeiro, RJ: Jorge Zahar. (Trabalho original publicado em 1960).

Lacan, J. (2003a). O seminário. Livro 9. A identificação. Recife, PE: Centro de Estudos Freudianos do Recife. (Trabalho original publicado em 1961-1962).

Lacan, J. (2003b). Problemas cruciais para a psicanálise: resumo do seminário 19641965 (pp. 206-209). (Trabalho original publicado em 1966).

Lacan, J. (2008). O seminário. Livro 16. De um Outro ao outro. Rio de Janeiro, RJ: Jorge Zahar. (Trabalho original publicado em 1968-1969).

Lacan, J. (2009). O seminário. Livro 18. De um discurso que não fosse semblante. Rio de Janeiro, RJ: Jorge Zahar. (Trabalho original publicado em 1971).

\section{Resumos}

(A Biblioteca de Babel eo Outro: Borges e Lacan)

In The Library of Babel, Borges dialogues with mathematics, logic, philosophy and psychopathology. This article promotes a methodological encounter of Borges 


\section{LITERATURA, ARTE, PSICOPATOLOGIA}

with Lacan, highlighting the articulation between literary fiction and formal thought. Through the topology of the torus, a structural homology is proposed between the Library and the Other, allowing a comparison of the different positions of the characters of the short story with those of the subject in the language.

Key words: Psychoanalysis, psychopathology, literature, topology

\section{(A Biblioteca de Babel eo Outro: Borges e Lacan)}

Dans La Bibliothèque de Babel, Borges a essayé des approches avec les mathématiques, la logique, la philosophie et la psychopathologie. Cet article promut une rencontre méthodologique entre Borges et Lacan, en surlignant l'articulation entre fiction littéraire et pensée formelle. Par la topologie du tore, on propose une homologie structurelle entre la Bibliothèque et l'Autre, en comparant les différentes positions des les personnages de la nouvelle avec celles du sujet dans le langage.

Mots clés: Psychanalyse, psychopathologie, literature, topologie

\section{(A Biblioteca de Babel eo Outro: Borges e Lacan)}

En La Biblioteca de Babel, Borges ensayó aproximaciones con las matemáticas, la lógica, la filosofía y la psicopatología. Este artículo promueve un encuentro metodológico de Borges con Lacan, afirmando la potencia de la articulación entre ficción literaria y pensamiento formal. A través de la topología del toro, se propone una homología estructural entre la Biblioteca y el Otro, comparando las diferentes posiciones de los personajes del cuento con las del sujeto en el lenguaje.

Palabras-clave: psicoanálisis, psicopatología, literatura, topología

(A Biblioteca de Babel eo Outro: Borges e Lacan)

In Die Bibliothek von Babel, Borges hat ein Dialog mit Mathematik, Logik, Philosophie und Psychopathologie. Dieser Artikel fördert eine methodische Begegnung zwischen Borges und Lacan zu heben die Artikulation zwischen literarischer Fiktion und formalen Gedanken hervor. Durch die Topologie des Torus wird eine strukturelle Homologie zwischen der Bibliothek und dem Anderen vorgeschlagen, um so einen Vergleich der verschiedenen Positionen der Personen der Kurzgeschichte mit des Subjekt in der Sprache zu ermöglichen.

Schlüsselwörter: Psychoanalyse, Psychopathologie, Literatur, Topologie

Citação/Citation: Triska, V. H. C., \& D’Agord, M. R. L. (2018, março). A Biblioteca de Babel e o Outro: Borges e Lacan. Revista Latinoamericana de Psicopatologia Fundamental, 21(1), 167-181. http://dx.doi.org/10.1590/1415-4714.2018v21n1p167.11 


\section{Editores do artigo/Editors: Vários}

Recebido/Received: $23.11 .2017 /$ 11.23.2017 Aceito/Accepted: 18.1 .2018 / 1.18.2018

Copyright: (C) 2009 Associação Universitária de Pesquisa em Psicopatologia Fundamental/ University Association for Research in Fundamental Psychopathology. Este é um artigo de livre acesso, que permite uso irrestrito, distribuição e reprodução em qualquer meio, desde que o autor e a fonte sejam citados / This is an open-access article, which permits unrestricted use, distribution, and reproduction in any medium, provided the original authors and sources are credited.

Financiamento/Funding: Os autores declaram não ter sido financiados ou apoiados / The authors have no support or funding funded to report.

Conflito de interesses/Conflict of interest: Os autores declaram que não há conflito de interesses / The authors have no conflict of interest to declare.

\section{Vitor Hugo Couto Triska}

Psicólogo; Psicanalista; Doutor em Psicologia Social e Institucional pela Universidade Federal do Rio Grande do Sul - UFRGS (Porto Alegre, RS, Br).

Dario Pederneiras 354/403

90630-090 Porto Alegre, RS, Br.

vhtriska@gmail.com

\section{Marta Regina de Leão D'Agord}

Psicóloga; Psicanalista; Doutora em Psicologia pela Universidade Federal do Rio Grande do Sul - UFRGS (Porto Alegre, RS, Br); Professora do PPG Psicanálise: Clínica e Cultura na pela Universidade Federal do Rio Grande do Sul - UFRGS (Porto Alegre, RS, Br); Editora associada na seção "Resenhas" da Revista Latinoamericana de Psicopatologia Fundamental. Rua Riveira 600 90670-160 Porto Alegre, RS, Br marta.dagord@ufrgs.br

This is an open-access article, which permits unrestricted use, distribution,

\section{BY-NC} and reproduction in any medium for non-commercial purposes provided the original authors and sources are credited. 